\title{
Duloxetine for the treatment of post-prostatectomy stress urinary incontinence
}

\author{
Donald Neff, MD; Amy Guise, MD; Michael L. Guralnick, MD; Peter Langenstroer, MD; William A. See, MD; \\ Kenneth M. Jacobsohn, MD; R. Corey O'Connor, MD
}

Department of Urology, Medical College of Wisconsin, Milwaukee, WI

Cite as: Can Urol Assoc J 2013;7(5-6):e260-2. http://dx.doi.org/10.5489/cuaj.318 Published online May 13, 2013.

\section{Abstract}

Objectives: Stress urinary incontinence (SUI) is a known complication following prostatectomy. Duloxetine, a combined serotonin/ norepinephrine reuptake inhibitor, can decrease SUI by increasing urethral sphincter contractility. We examined the outcomes of patients with mild to moderate post-prostatectomy SUI treated with duloxetine.

Methods: We conducted a retrospective review of men treated with duloxetine to manage mild to moderate post-prostatectomy SUI from 2006 to 2012. All patients received oral duloxetine $30 \mathrm{mg}$ once a week, then $60 \mathrm{mg}$ thereafter. Patients were seen one month later to determine drug efficacy and side effects.

Results: In total, 94 men were included in the study. Daily pad usage decreased from 2.9 (range: $1-5)$ to 1.6 (range: $0-4)(p<0.05)$. Incontinence Impact Questionnaire (IIQ-7) scores decreased from 13.0 (range: $6-18)$ to 7.9 (range: $2-16)(p<0.05)$. Linear satisfaction scores improved from 0.8 (range: $0-2)$ to 2.0 (range: $1-3)(p<0.05)$. Following a 1-month duloxetine trial, 33/94 (35\%) men reported satisfactory SUI improvement and requested to continue the medication. The drug was discontinued in $61 / 94$ (65\%) patients due to poor efficacy in 32/94 (34\%), intolerable side effects in 14/94 (15\%) or both in 15/94 (16\%). Reported side effects included fatigue, light-headedness, insomnia, nausea and dry mouth.

Conclusions: Duloxetine improved post-prostatectomy SUI in $47 / 94(50 \%)$ men following a 1-month trial. However, only 33/94 (35\%) patients were able to tolerate the drug. Duloxetine may be considered a treatment option for men with mild to moderate post-prostatectomy SUI.

\section{Introduction}

Stress urinary incontinence (SUI) is a known complication of radical prostatectomy that may persist in up to $90 \%$ of patients 1 year after the procedure. ${ }^{1}$ When compared to individuals who are continent, patients with incontinence have a higher level of anxiety, lower quality of life (QOL) and poorer life satisfaction. ${ }^{2}$ Traditionally, treatment options for post-prostatectomy SUI have involved surgical intervention. Placement of an artificial urinary sphincter remains the gold standard, with success rates up to $90 \%{ }^{3}$ However, the procedure is invasive and the need for surgical revision is common. ${ }^{4}$

Duloxetine, a selective serotonin (5-HT) and norepinephrine $(\mathrm{NE})$ reuptake inhibitor, has been shown to decrease SUI by increasing urethral sphincter contractility. ${ }^{5}$ The drug inhibits the pre-synaptic reuptake of 5-HT and NE at Onuf's nucleus in the sacral spinal cord. The result is an increase in rhabdosphincter activity due to increased post-synaptic receptor stimulation. This unique pharmacotherapy has demonstrated efficacy in the management of female SUI and has been approved for this use in Europe since 2004. ${ }^{6}$

The use of duloxetine in men is an active area of investigation and represents a potential nonsurgical therapy for post-prostatectomy SUI., ${ }^{5-10}$ The goal of our investigation is to evaluate the efficacy and reported side effects in patients with mild to moderate post-prostatectomy SUI treated with duloxetine.

\section{Methods}

After receiving institutional review board approval, we performed a retrospective chart review of all men treated at a single institution from 2006 to 2012 for mild to moderate post-prostatectomy SUI. Mild to moderate SUI was defined as urethral leakage with physical activity requiring $\leq 5$ absorptive pads per day. Exclusion criteria included previous anti-incontinence surgery, post-void residual bladder volume $>100 \mathrm{~mL}$, urinary incontinence requiring $>5$ pads per day, previous pelvic irradiation/cryotherapy or clinical urge urinary incontinence. Select patients underwent video urodynamic testing and cystoscopy to confirm SUI and/or evaluate the vesicourethral anastomosis. Data extracted included patient age, daily pad usage, previous SUI thera- 
pies, pre- and post-incontinence impact questionnaire (IIQ7) scores, pre- and post-linear satisfaction score (0 [unsatisfied] to 3 [greatly satisfied]) and medication side effects. All patients received oral duloxetine $30 \mathrm{mg}$ at bedtime for 1 week, then $60 \mathrm{mg}$ at bedtime thereafter. Patients were seen 1 month after the start of pharmacotherapy to determine drug efficacy and side effects. Statistical significance was determined using Fisher's exact test.

\section{Results}

Ninety-four patients were included in the study. Mean patient age was 64.3 years (range: $47-83$ ). The average time since radical prostatectomy was 19.3 months (range: 9-49). We tallied the pre- and post-treatment pad usage, IIQ-7 scores and linear satisfaction scores (Table 1). Following a 1-month trial of duloxetine, 51/94 (54\%) patients reported a $\geq 50 \%$ reduction in daily pad usage. Satisfactory SUI reduction and drug tolerability was reported in 33/94 (35\%) men. The improvement in daily pad usage, IIQ-7 scores and QOL scores all reached statistical significance $(p<0.05)$. The drug was discontinued in $61 / 94(65 \%)$ patients due to lack of efficacy in $32 / 94(34 \%)$, intolerable side effects in 14/94 (15\%) or both in 15/94 (16\%). Reported intolerable side effects included fatigue $(12 \%)$, light-headedness $(11 \%)$, insomnia $(3 \%)$, nausea $(3 \%)$ and dry mouth $(2 \%)$.

\section{Discussion}

Multiple factors may contribute to the risk of SUI following radical prostatectomy including age, preoperative continence status, surgeon experience, education level, concomitant pulmonary disease and need for adjuvant radiation therapy to the prostatic bed. ${ }^{11,12}$ The etiologies of SUI after prostatectomy include injury to the nerve, muscle fibers or support structures of the external urethral sphincter (EUS). ${ }^{13-15}$ The somatic and autonomic neural innervation of the EUS arise from Onuf's nucleus of the sacral cord. ${ }^{16-18}$ The postsynaptic autonomic neurons of the EUS have a high density of serotonergic and noradrenergic terminals. Blocking the reuptake of NE and 5-HT in the pre-synaptic adrenergic nerve results in increased EUS contractility secondary to increased stimulation of the post-synaptic 5-HT and NE receptors. ${ }^{19}$

Several clinical studies investigating the role of duloxetine in post-prostatectomy SUI have been published. ${ }^{5,7-10}$ Filocamo and colleagues reported duloxetine and pelvic floor physical therapy may allow for earlier return to continence as compared to physical therapy alone following catheter removal in the immediate postoperative period. ${ }^{7}$ Similarly, two additional studies found an approximate $50 \%$ reduction in pad usage with patients taking duloxetine to manage post-prostatectomy SUI. ${ }^{5,8}$ Zarariou and colleagues

\begin{tabular}{l}
$\begin{array}{l}\text { Table 1. Changes in mean pad usage, IIQ-7 scores and } \\
\text { linear satisfaction scores after one month of duloxetine } \\
\text { pharmacotherapy }\end{array}$ \\
\begin{tabular}{lccc}
\hline & Baseline & After treatment & p value \\
\hline $\begin{array}{l}\text { Mean daily pad usage } \\
\text { (range) }\end{array}$ & $2.9(1-5)$ & $1.6(0-4)$ & $<0.05$ \\
$\begin{array}{l}\text { Mean IIQ-7 score (range) } \\
\text { Mean linear satisfaction }\end{array}$ & $13.0(6-18)$ & $7.9(2-16)$ & $<0.05$ \\
score (range) & $0.8(0-2)$ & $2.0(1-3)$ & $<0.05$ \\
\hline IIO: Incontinence Impact Questionnaire. & & &
\end{tabular} \\
\hline
\end{tabular}

reported minimal urodynamic improvements, but a significant reduction in clinical pad use after a 3-month course of duloxetine. ${ }^{9}$ A Spanish study evaluated the efficacy of duloxetine in 68 patients with post-prostatectomy SUI at least 1 year post-prostatectomy. ${ }^{10}$ The authors reported statistically significant improvements in daily pad requirements and incontinence questionnaire results. Our findings were similar with $47 / 94(50 \%)$ confirming satisfactory drug efficacy and 51/94 (54\%) men reporting a $>50 \%$ reduction in daily pad usage. Overall, IIQ-7 and QOL scores demonstrated statistically significant improvements following a 30-day trial of duloxetine.

Side effects are common with duloxetine. In our study, 29/94 (31\%) patients chose to discontinue therapy secondary to intolerable adverse drug effects. Reported side effects included fatigue, light-headedness, insomnia, nausea and dry mouth. The discontinuation rate in our study is comparable to other published studies. . $^{\text {7-10 }}$

Other pharmacologic agents have been investigated for the treatment of post-prostatectomy SUI. Alpha-adrenergic agonists, including midodrine, norephrine and ephedrine, as well as beta-2-antagonists, have been used. However, the lack of receptor selectivity and severe systemic side effects have limited their clinical use. ${ }^{20,21}$ Although imipramine, a tricyclic antidepressant with 5-HT and NE reuptake properties, has shown efficacy for post-prostatectomy incontinence, doses required to achieve success have significant anticholinergic side effects. ${ }^{22}$ Venlafaxine, a 5-HT/NE reuptake inhibitor similar to duloxetine, has also been studied with positive results. ${ }^{23,24}$

Our study is limited by its retrospective nature and small sample size. Pad usage was used as an outcome measure, but this may not accurately quantify the magnitude of incontinence since the type of pad used was not standardized. As well, the follow-up is short and durability of the results is unknown. Clinically, our patients electing to continue duloxetine have not reported tachyphylaxis. The study, however, does add to the literature supporting further investigation of this medication for the treatment of post-prostatectomy stress incontinence. 
Neff et al.

\section{Conclusion}

The surgical complication of post-prostatectomy SUI can result in decreased QOL. Many patients are reluctant to undergo an additional surgical procedure to address this problem. Our data indicate that duloxetine is a promising non-invasive medical treatment option for mild to moderate post-prostatectomy incontinence.

Competing interests: None declared.

This paper has been peer-reviewed.

\section{References}

1. Peterson AC, Chen Y. Patient reported incontinence after radical prostatectomy is more common than expected and not associated with the nerve sparing technique: results from the Center for Prostate Disease Research (CPDR) database. Neurourol Urodyn 2012;31:60-3. http://dx.doi.org/10.1002/nau.21189

2. Schroeck FR, Krupsky TL, Sun L, et al. Satisfaction and regret after open retropubic or robot assisted laparoscopic radical prostatectomy. Eur Urol 2008;54:785-93. http://dx.doi.org/10.1016/i.eururo.2008.06.063

3. Tse V, Stone AR. Incontinence after prostatectomy: the artificial urinary sphincter. BJU Int 2003;92:886-9. http://dx.doi.org/10.1111/i.1464-410X.2003.04517.x

4. Clemens JQ, Schuster TG, Konnak JW, et al. Revision rate after artificial urinary sphincter implantation for incontinence after radical prostatectomy: actuarial analysis. J Urol 2001;166:1372-5. http://dx.doi. org/10.1016/S0022-5347(05)65772-2

5. Schlenker B, Gratzke $C$, Reich 0 , et al. Preliminary results on the off-label use of duloxetine for the treatment of stress incontinence after radical prostatectomy or cystectomy. Eur Urol 2006;49:1075-8. http://dx.doi.org/10.1016/i.eururo.2006.01.038

6. Boy S, Reitz A, Wirth B, et al. Facilitatory neuromodulative effect of duloxetine on pudendal motor neurons controlling urethral pressure: a functional urodynamic study in healthy women. Eur Urol 2006;20:119-25. http://dx.doi.org/10.1016/i.eururo.2005.12.020

7. Filocamo MT, Li Marzi V, Del Popolo G, et al. Pharmacologic treatment in postprostatectomy stress urinary incontinence. Eur Urol 2007;51:1559-64. http://dx.doi.org/10.1016/j.eururo.2006.08.005

8. Fink KG, Huber J, Wurnschimmel $\mathrm{E}$, et al. The use of duloxetine in the treatment of male stress urinary incontinence. Wien Med Wochenschr 2008;158:116-8. http://dx.doi.org/10.1007/s10354-0070494-7

9. Zahariou A, Papaioannou P, Kalogirou G. Is HCl duloxetine effective in the management of urinary stress incontinence after radical prostatectomy? Urol Int 2006;77:9-12. http://dx.doi.org/10.1159/000092927
10. Collado Serra A, Rubio Briones J, Puyol Payas $M$, et al. Postprostatectomy established stress urinary incontinence treated with duloxetine. Urology 2011;78:261-6. http://dx.doi.org/10.1016/j.urology.2011.03.006

11. Nam RK, Herschorn S, Loblaw DA, et al. Population based study of long-term rates of surgery for urinary incontinence after radical prostatectomy for prostate cancer. J Urol 2012;188:502-6. http://dx.doi. org/10.1016/i.juro.2012.04.005

12. Nilsson AE, Schumacher MC, Johansson E, et al. Age at surgery, educational level and long-term urinary incontinence after radical prostatectomy. BJU Int 2011;108:1572-7. http://dx.doi.org/10.1111/ i.1464-410X.2011.10231.x

13. Eastham JA, Kattan MW, Rogers E, et al. Risk factors for urinary incontinence after radical prostatectomy. J Urol 1996;156:1707-13. http://dx.doi.org/10.1016/S0022-5347(01)65488-0

14. Thor KB. Serotonin and norepinephrine involvement in efferent pathways to the urethral rhabdosphincter: implications for treating stress urinary incontinence. Urology 2003;62(4 Suppl 1):3-9. http://dx.doi. org/10.1016/S0090-4295(03)00754-4

15. Rehder $\mathrm{P}$, Gozzi C. Transobturator sling suspension for male urinary incontinence including post-radical prostatectomy. Eur Urol 2007;52:860-6. http://dx.doi.org/10.1016/i.eururo.2007.01.110

16. Ramírez-León V, Hökfelt T, Cuello AC, et al. Enkephalin, thyrotropin-releasing hormone and substance $P$ immunoreactive azonal innervation of the ventrolateral dendritic bundle in the cat sacral spinal cord: an ultrastructural study. J Chem Neuroanat 1994;7:203-15. http://dx.doi.org/10.1016/08910618(94)90013-2

17. Ramírz-León V, Ulfhake B, Arvidsson U, et al. Serotoninergic, peptidergic and GABAergic innervation of the ventrolateral and dorsolateral motor nuclei in the cat $\mathrm{S1} / \mathrm{S} 2$ segments: an immunofluorescence study. J Chem Neuroanat 1994;7:87-103. http://dx.doi.org/10.1016/0891-0618(94)90010-8

18. Elbadawi A, Schenk EA. A new theory of the innervation of bladder musculature: innervation of the vesicourethral junction and external urethral sphincter. J Urol 1974;111:613-5.

19. Tsakiris P, de la Rosette JJ, Michel MC, et al. Pharmacologic treatment of male stress urinary incontinence: systematic review of the literature and levels of evidence. Euro Urol 2008;53:53-9. http://dx.doi. org/10.1016/i.eururo.2007.09.037

20. Zinner NR, Koke SC, Viktrup L. Pharmacotherapy for stress urinary incontinence - present and future options. Drugs 2004;64:1503-16. http://dx.doi.org/10.2165/00003495-200464140-00001

21. Castro-Diaz D, Amoros MA. Pharmacotherapy for stress urinary incontinence. Curr Opin Urol 2005;15:22730. http://dx.doi.org/10.1097/01.mou.0000172394.60481.47

22. Nitti VW. Duloxetine: a new pharmacologic therapy for stress urinary incontinence. Rev Urol 2004;6(Suppl 3):S48-55.

23. Bae JH. The effects of a selective noradrenaline reuptake inhibitor on the urethra: an in vitro and in vivo study. BJU Int 2001;88:771-5. http://dx.doi.org/10.1046/i.1464-4096.2001.02389.x

24. Erdinc $A$, Gurates $B$, Celik $H$, et al. The efficacy of venlafaxine in the treatment of women with stress urinary incontinence. Gynecol Obstet 2009;279:343-8.

Correspondence: Dr. R. Corey O'Connor, Associate Professor of Urology, Department of Urology, Medical College of Wisconsin, 9200 W. Wisconsin Ave., Milwaukee, WI 53226; fax: 414-8050771; Corey0C@aol.com 